\title{
Characterization of Free-range Indigenous Chicken Production System in North-East India (Assam)
}

\author{
Rafiqul Islam ${ }^{1 *}$, Niranjan Kalita ${ }^{2}$, Deben Sapcota ${ }^{3}$, Islam Uddin Sheikh ${ }^{4}$, \\ Joga Dev Mahanta ${ }^{5}$ and Mihir Sarma ${ }^{6}$ \\ ${ }^{1}$ Department of Animal Husbandry and Dairying, BNCA, Biswanath Chariali, Assam, INDIA \\ ${ }^{2}$ Directorate of Research (Veterinary), Assam Agricultural University, Khanapara, Assam, INDIA \\ ${ }^{3,5}$ Department of Poultry Science, College of Veterinary Science, AAU, Khanapara, Assam, INDIA \\ ${ }^{4}$ Division of Livestock Production and Management, SKUAST-Kashmir, UT of JEK, INDIA \\ ${ }^{6}$ Livestock Research Station, Mondira, Assam Agricultural University, Guwahati, INDIA \\ *Corresponding author: R Islam; E-mail: rafiqul.islam@aau.ac.in
}

\begin{abstract}
A survey was undertaken in four agro-climatic zones of Assam to explore the existing free-range indigenous chicken farming system. Data were collected from 200 farmers, selected randomly by personal interviews with structured questionnaire. Results on existing free-range chicken production system were analyzed and documented. The overall mean age of the chicken farmer was $37.95 \pm 0.77$ years. The primary purpose of chicken rearing was to meet day to day petty expenses $(49.50 \%)$ and selfconsumption $(24.50 \%)$. The overall mean flock size recorded as $29.79 \pm 0.28$ number per household and the flocks were mostly comprised of chicks. Majority (63\%) of the chicken coop were constructed inside the dwelling house without any specifications with locally available materials. The study also indicated that indigenous chicken production was characterized by scavenging with supplemental feeds. Primarily home produced eggs were used for natural incubation by broody hen or duck. Newcastle (Ranikhet) disease was the most fatal disease that caused heavy mortality in indigenous chicken flock as reported by 84.5 per cent of the respondents. Farmers seldom vaccinated their birds against any diseases, but none of them practiced deworming. Chickens were mostly sold as live chicken. Eggs were mostly collected from farmers' doorstep by hawkers. The study indicated that the indigenous chicken played a significant role in nutritional and livelihood of rural smallholders.
\end{abstract}

\section{HIGHLIGHTS}

0 Majority of the chicken farmers were women.

0 The main purpose of rearing indigenous was to meet day to day petty expenses.

Keywords: Backyard, chicken, husbandry practices, disease, marketing

Free range scavenging poultry production is the most common phenomena among landless and underprivileged section of the rural world. In most of the underdeveloped and developing countries free range scavenge chicken contributes several livelihood indicators like income, nutrition, food security, savings, insurance and gender equality. In India, backyard poultry has found special favour with the poor (landless, marginal and small farmers), tribal, scheduled castes and other backward classes and supplement and enhance their livelihoods to climb the poverty ladder as well as asset accumulation (Mandal et al., 2006; Shinde et al., 2006). The state of Assam has a total poultry population of 46.7 million and contributes 5.48 per cent of country's poultry population (GOI, 2019). More than 96 per cent of total poultry in Assam

How to cite this article: Islam, R., Kalita, N., Sapcota, D., Sheikh, I.U., Mahanta, J.D. and Sarma, M. (2021). Characterization of free-range indigenous chicken production system in north-east India (Assam). J. Anim. Res., 11(1): 59-70.

Source of Support: None; Conflict of Interest: None 
are reared under backyard system (BAHS, 2016). The total egg production in Assam is 34.66 lakh, out of which 33.05 lakhs $(95.35 \%)$ is contributed by our indigenous chicken. So, backyard chicken has significant contribution to egg and meat production in Assam's economy, despite their poor production potential. It is the primary source of protein in rural North-east India, where more than 70 per cent children are suffering from malnutrition and most of the pregnant women are suffering from anemia. To curb this menace, backyard poultry farming can be one of the best options in rural Assam. Further, the rural people of Assam have been rearing poultry for many reasons like to generate income, for home consumption and for sociocultural reasons. In spite of these, very little initiative has been taken by the Government and private sector, policy makers, researchers and other stakeholders to develop this sector. Hence, before taking any development project on free range rural poultry, it is very necessary to know the present status of this sector, which will help the stakeholders to design and formulate the strategy for development. Keeping all these points in mind the present investigation was undertaken to study the present status of indigenous chicken production system, which could provide information to design sustainable village chicken development programme for different stakeholders.

\section{MATERIALS AND METHODS}

Out of the six agro-climatic zones of Assam (Fig. 1), the study was conducted in four agro-climatic zones viz. Upper Brahmaputra Valley Zone (UBVZ), Lower Brahmaputra Valley Zone (LBVZ), North Bank Plain Zone (NBPZ) and Central Brahmaputra Valley Zone (CBVZ). One district from each zone were selected, thus a total of four districts viz. Sivasagar, Dhubri, Nagaon and Sonitpur were selected. Fifty farmers from each district (10 villages from each district; 5 farmers from each village) were selected randomly and thus a total of 200 farmers were used for the study. A well structured questionnaire was developed containing all relevant information set for the study. Then the schedule was pre-tested in the actual field condition and appropriate modification was made in the schedule for final use. The data were collected during the month of August, 2017 to July, 2018 by personal interview and by observation and discussion. The responses of the respondents were immediately recorded in the interview schedule.

\section{Analysis of data}

The raw data so obtained on various parameters were compiled, tabulated and systematically classified and subjected to appropriate statistical analysis using SPSS version 20. Descriptive statistics such as mean, range and percentile were used. Chi-square test was employed for ordinal and nominal data such as chicken management practice like feeding, watering, housing and breeding.

\section{RESULTS AND DISCUSSION}

\section{Socio-economic profile of the respondents}

The study indicated that overall mean age of the surveyed farmers was $37.95 \pm 0.77$ years (Table 1 ). The age recorded in LBVZ was significantly $(\mathrm{P}<0.05)$ higher than UBVZ. The value recorded in CBVZ was comparable with NBPZ. Involvement of such age group of people pointed out that indigenous chicken farming was in the hands of young, energetic who had a great mental strength to take risk bearing activities and could adopt innovative ideas. The present results corroborated the findings of Gazi et al. (2014) and Dumrya et al. (2015), while Balamurugan et al. (2017) and Bharti et al. (2018) reported comparatively lower age group of farmers engaged in chicken farming. The survey results also showed that most $(83 \%)$ of the respondents were women (Table 1). Kumar et al. (2013) and Tudu et al. (2015) also indicated the similar results regarding sex of the respondents. Participation of the rural women indicated empowerment of women and optimum use of family labour through chicken farming. More than half $(57.5 \%)$ of the respondents had only primary level of education (Table 1). Poor educational background among the farmers might influence the adoption of scientific indigenous chicken farming technology negatively. Agriculture along with animal husbandry provided occupational livelihood to around 40 per cent of the farmers indicated that indigenous chicken farming was part and parcel of their livelihood. The chi square value indicated that there were significant $(\mathrm{P}<0.05)$ differences of occupation among different zones. Majorities (74\%) of the chicken farmers were landless to marginal farmers and average land holding was $1.35 \pm 0.09$ acres. The average land holding in UBVZ was significantly $(\mathrm{P}<0.05)$ higher than LBVZ and was comparable with CBVZ and NBPZ. Gazi et al. (2014) also reported that majority (54.3\%) 
Table 1: Socio-economic profile of the respondents

\begin{tabular}{|c|c|c|c|c|c|c|}
\hline Variables & $\begin{array}{l}\text { UBVZ } \\
\mathbf{N}=\mathbf{5 0}\end{array}$ & $\begin{array}{l}\text { LBVZ } \\
\mathbf{N}=\mathbf{5 0}\end{array}$ & $\begin{array}{l}\text { CBVZ } \\
\mathbf{N}=\mathbf{5 0}\end{array}$ & $\begin{array}{l}\text { NBPZ } \\
\mathbf{N}=\mathbf{5 0}\end{array}$ & $\begin{array}{l}\text { Overall } \\
\mathbf{N}=\mathbf{2 0 0}\end{array}$ & $\begin{array}{l}\text { Chi-square } \\
\text { value }\end{array}$ \\
\hline Age (Years) & $33.64^{\mathrm{a}}$ & $41.74^{\mathrm{b}}$ & $38.94^{\mathrm{bc}}$ & $37.48^{\mathrm{ac}}$ & $37.95 \pm 0.77$ & $\mathrm{P}=5.13^{*}$ \\
\hline \multicolumn{7}{|l|}{ Sex of respondents $(\%)$} \\
\hline Male & 8.00 & 22.00 & 26.00 & 12.00 & 17.00 & \multirow{2}{*}{7.51} \\
\hline Female & 92.00 & 78.00 & 74.00 & 88.00 & 83.00 & \\
\hline \multicolumn{7}{|l|}{ Level of education (\%) } \\
\hline No formal schooling & 4.00 & 14.00 & 10.00 & 8.00 & 9.00 & \multirow{4}{*}{18.13} \\
\hline Primary & 48.00 & 68.00 & 60.00 & 54.00 & 57.50 & \\
\hline High school & 34.00 & 16.00 & 22.00 & 26.00 & 24.50 & \\
\hline$\geq$ Higher secondary & 14.00 & 2.00 & 8.00 & 12.00 & 9.00 & \\
\hline \multicolumn{7}{|l|}{ Occupation (\%) } \\
\hline Agriculture & 16.00 & 54.00 & 36.00 & 40.00 & 36.50 & \multirow{4}{*}{$32.36^{*}$} \\
\hline A.H. \& Agriculture & 64.00 & 22.00 & 38.00 & 34.00 & 39.50 & \\
\hline Daily wager & 10.00 & 24.00 & 20.00 & 24.00 & 19.50 & \\
\hline Others & 10.00 & 0.00 & 6.00 & 2.00 & 4.50 & \\
\hline \multicolumn{7}{|l|}{ Marital status (\%) } \\
\hline Married & 60.00 & 74.00 & 58.00 & 66.00 & 64.50 & \multirow{3}{*}{10.11} \\
\hline Unmarried & 14.00 & 10.00 & 24.00 & 20.00 & 17.00 & \\
\hline Widow/divorce & 26.00 & 16.00 & 18.00 & 14.00 & 18.50 & \\
\hline Annual income (US\$) (\%) & $895.96^{\mathrm{a}}$ & $456.30^{\mathrm{b}}$ & $694.46^{\mathrm{c}}$ & $706.68^{\mathrm{d}}$ & $688.35 \pm 19.67$ & $\mathrm{P}=30.20^{*}$ \\
\hline Land holding (Acre) $(\%)$ & $1.51^{\mathrm{a}}$ & $0.84^{\mathrm{b}}$ & $1.59^{\mathrm{a}}$ & $1.46^{\mathrm{a}}$ & $1.35 \pm 0.09$ & $\mathrm{P}=4.23 *$ \\
\hline \multicolumn{7}{|l|}{ Owner of the flock (\%) } \\
\hline Mother & 74.00 & 60.00 & 70.00 & 66.00 & 67.50 & \multirow{3}{*}{3.43} \\
\hline Father & 10.00 & 16.00 & 8.00 & 10.00 & 11.00 & \\
\hline Children & 16.00 & 24.00 & 22.00 & 24.00 & 21.50 & \\
\hline \multicolumn{7}{|l|}{ Purpose of chicken rearing (\%) } \\
\hline Self consumption & 38.00 & 12.00 & 16.00 & 32.00 & 24.50 & \multirow{4}{*}{$21.77^{*}$} \\
\hline To meet petty expenses & 40.00 & 62.00 & 54.00 & 42.00 & 49.50 & \\
\hline For customs & 8.00 & 6.00 & 22.00 & 14.00 & 12.50 & \\
\hline To entertain guests & 14.00 & 20.00 & 8.00 & 12.00 & 13.50 & \\
\hline $\begin{array}{l}\text { Experience in chicken farming } \\
\text { (Years) }\end{array}$ & 13.06 & 11.30 & 12.76 & 12.10 & $12.76 \pm 0.79$ & $\mathrm{P}=0.99$ \\
\hline
\end{tabular}

chicken farmers had no land in the state of West Bengal, India. The average annual income of farmer was found as $\$ 688.35 \pm 19.67$. The mean annual income recorded in UBVZ was significantly $(\mathrm{P}<0.05)$ higher than other zones. The surveys also revealed that majority $(64.5 \%)$ of the farmers were married. In earlier studies, Bharti et al. (2018) and Roselin et al. (2015) also recorded higher per cent of married women engaged in indigenous chicken farming.

\section{Ownership of the flock}

The majority $(67.5 \%)$ of the indigenous chicken farmers were mother, followed by children $(21.5 \%)$ and father $(11.0 \%)$ as shown in Table 1 . As in maximum cases, the women folk hold the ownership of indigenous chicken (Yusuf et al., 2014; Fida et al., 2018) hence decisions for hatching, culling of surplus chicken, selling of eggs and live birds etc. were made by the women resulted in women empowerment in rural areas. 


\section{Experience in chicken farming}

The overall mean experience of the farmer in chicken farming was recorded as $12.76 \pm 0.79$ years (Table 1). In Ethiopia, village chicken owners had an average experience of 12.5 years as reported by Moges et al. (2010). The results also showed that most (62.5\%) of the respondents had more than 10 years experience in indigenous chicken rearing. In the present study, although the farmers had more than 10 years of experience (Shahjahan and Bhuiyan, 2016), they anticipated havoc loss because of disease incidence, which might be due to lack of scientific knowledge on chicken rearing.

\section{Purpose of rearing chicken}

It was found that almost half $(49.5 \%)$ of the respondents reared indigenous chicken to meet petty expenses such as children school fee, cosmetics, mobile phone bills etc. However, one-fourth of the farmers reared chicken for home consumption, while 13.5 and 12.5 per cent of the respondents reared chicken for entertaining guests and for customs and festivals respectively (Table 1$)$. There was significant $(\mathrm{P}<0.05)$ difference among zones for purpose of rearing chicken. The study indicated that purpose of indigenous chicken rearing was from cash income (Moges et al., 2010; Bharti et al., 2018) to nutritional security (Muchadeyi et al., 2004) in a rural family. Similarly, Fisseha et al (2010a) reported that the major purposes of chicken rearing in Bure district were: sale for cash income $(51 \%)$, egg hatching for breeding/replacement stock (45\%), home consumption (44\%), egg production $(40.7 \%)$ and use of chicken for cultural and/or religious ceremonies $(36.4 \%)$ in the order of importance.

\section{Husbandry Practices}

\section{Flock size and composition}

The flock size ranged from $29.04 \pm 0.55$ to $30.24 \pm 0.55$ with an overall mean of $29.79 \pm 0.28$ (Table 2). The flock size did not vary significantly $(\mathrm{P}<0.05)$ among different zones.

Comparatively lower flock size reported by Rawat et al. (2015) and Kumar et al. (2013) as 22.53 and 5.6 birds in India. The difference in flock size might be attributed to seasons, culling, disease outbreak and predation (Moges et al., 2010). The study also revealed that the flock of indigenous chicken mostly constituted by chicks (62.01\%), followed by growers (21.42\%) and adults (16.56\%). Hussain et al. (2017) also reported chicken flock mostly comprised of chicks followed by adults in Jammu and Kashmir, India. In contrary, Keqa et al. (2017) found that chicken flock was dominated by adults followed by growers and chicks in Solomon Islands.

\section{Housing management}

The main purposes of housing of indigenous chicken were night sheltering $(56.5 \%)$ followed by to prevent predation $(34 \%)$ and extreme climatic conditions $(9.5 \%)$ as depicted in Table 3. Temporary housing for night sheltering (Yusuf et al., 2014) and permanent housing for providing protection against predators (Mapiye and Sibanda, 2005) were common to household in different parts of the world. Lack of proper housing facilities for indigenous chicken might be due to lack of awareness, cost and availability of housing materials. Majority $(63 \%)$ of the chicken coops were located inside the dwelling house. The location of coop

Table 2: Flock size and flock composition of indigenous chicken

\begin{tabular}{|c|c|c|c|c|c|}
\hline \multirow{2}{*}{ Variables } & UBVZ & LBVZ & CBVZ & NBPZ & Overall \\
\hline & $\mathbf{N}=\mathbf{5 0}$ & $\mathbf{N}=\mathbf{5 0}$ & $\mathbf{N}=\mathbf{5 0}$ & $\mathbf{N}=\mathbf{5 0}$ & $\mathrm{N}=\mathbf{2 0 0}$ \\
\hline Flock size (Number) & 29.72 & 29.04 & 30.16 & 30.24 & $29.79 \pm 0.28$ \\
\hline Flock composition & $\mathrm{N}=1486$ & $\mathrm{~N}=1452$ & $\mathrm{~N}=1508$ & $\mathrm{~N}=1512$ & $\mathrm{~N}=5958$ \\
\hline Chicks (0-9 weeks) & 66.02 & 57.23 & 59.81 & 65.01 & 62.01 \\
\hline Growers (10-20 weeks) & 22.01 & 22.80 & 22.80 & 18.78 & 21.42 \\
\hline Adults ( $>20$ weeks) & 11.98 & 19.97 & 18.78 & 16.20 & 16.56 \\
\hline
\end{tabular}


Table 3: Housing management adopted by the respondents

\begin{tabular}{|c|c|c|c|c|c|c|}
\hline Variables & $\begin{array}{l}\text { UBVZ } \\
\mathbf{N}=\mathbf{5 0}\end{array}$ & $\begin{array}{l}\text { LBVZ } \\
\mathbf{N}=\mathbf{5 0}\end{array}$ & $\begin{array}{l}\text { CBVZ } \\
\mathbf{N}=50\end{array}$ & $\begin{array}{l}\text { NBPZ } \\
\text { N=50 }\end{array}$ & $\begin{array}{l}\begin{array}{l}\text { Overall } \\
\mathbf{N}=\mathbf{2 0 0}\end{array}\end{array}$ & Chi-square value \\
\hline \multicolumn{7}{|l|}{ Purpose of housing $(\%)$} \\
\hline Night sheltering & 68.00 & 52.00 & 44.00 & 62.00 & 56.50 & 10.84 \\
\hline To prevent extreme climate & 8.00 & 6.00 & 10.00 & 14.00 & 9.50 & \\
\hline To prevent predation & 24.00 & 42.00 & 46.00 & 24.00 & 34.00 & \\
\hline \multicolumn{7}{|l|}{ Location of the $\operatorname{coop}(\%)$} \\
\hline Inside dwelling house & 66.00 & 50.00 & 74.00 & 62.00 & 63.00 & 19.58 \\
\hline Outside dwelling house & 24.00 & 30.00 & 18.00 & 34.00 & 26.50 & \\
\hline Inside livestock shed & 10.00 & 20.00 & 8.00 & 4.00 & 10.50 & \\
\hline \multicolumn{7}{|c|}{ Materials used in construction of coop (\%) } \\
\hline \multicolumn{7}{|l|}{ Floor } \\
\hline Mud & 14.00 & 24.00 & 12.00 & 28.00 & 19.50 & 8.90 \\
\hline Concrete & 2.00 & 0.00 & 6.00 & 4.00 & 12.00 & \\
\hline Bamboo or wooden slated & 84.00 & 76.00 & 82.00 & 68.00 & 77.50 & \\
\hline \multicolumn{7}{|l|}{ Wall } \\
\hline Bamboo or wooden slates & 70.00 & 74.00 & 76.00 & 70.00 & 72.50 & 5.19 \\
\hline G. I Sheet & 26.00 & 26.00 & 20.00 & 30.00 & 25.50 & \\
\hline Mud & 4.00 & 0.00 & 4.00 & 0.00 & 2.00 & \\
\hline \multicolumn{7}{|l|}{ Roof } \\
\hline G. I. Sheet & 84.00 & 92.00 & 86.00 & 90.00 & 87.50 & 2.94 \\
\hline Bamboo or wooden slates & 14.00 & 6.00 & 12.00 & 8.00 & 10.00 & \\
\hline Thatch & 4.00 & 2.00 & 2.00 & 2.00 & 2.50 & \\
\hline \multicolumn{7}{|c|}{ Frequency of cleaning coop $(\%)$} \\
\hline Daily & 00 & 00 & 00 & 00 & 00 & 0.00 \\
\hline Weekly & 22.00 & 42.00 & 32.00 & 42.00 & 34.50 & \\
\hline Monthly & 62.00 & 30.00 & 48.00 & 32.00 & 43.00 & \\
\hline Not cleaned & 16.00 & 28.00 & 20.00 & 26.00 & 22.50 & \\
\hline
\end{tabular}

inside the dwelling house might be attributed to protection of chicken from predators and cost and availability of the construction materials (Nigussie et al., 2015). However, coops inside dwelling house might be attributed to lack of scientific knowledge of chicken rearing because same might cause foul odour and unhygienic condition inside the dwelling house due to faeces and other dirt objects. However, the coops were also found outside the dwelling house $(26.5 \%)$, while some $(10.5 \%)$ of them kept chicken in livestock shed (Table 3).

Proper housing management might lead to better sanitation; avoid predation and theft and overall better production. The results indicated that the coops were mostly constructed with some low cost locally available materials such as corrugated G.I. sheet, wooden and bamboo plates. Floors were mostly mud floor (77.5\%), while walls and roofs were chiefly constructed with bamboo or wooden slates and G.I. sheet respectively. Similarly, Kumar et al. (2013) and Chaturvedani et al. (2016) also reported that small coops were constructed for indigenous chicken, which were chiefly made of locally available materials viz., bamboo, mud, wood, net, tin and straw. The results revealed that none of the respondents cleaned their chicken coop on daily basis, while majority $(43 \%)$ of them cleaned it on monthly basis and few of them did not clean the coop. This might be due to lack of awareness among the farmers. Cleaning of coop on daily basis might provide better hygiene and health condition of the birds. Contrary to the present findings, Chutia (2010) 
reported that majority of the respondents cleaned coop daily in Assam, India.

\section{Feeding and watering management}

In addition to scavenging, all the farmers provided supplemental feeds to their chicken. Among the supplemental feeds, mostly grains $(65.5 \%)$ were provided, followed by-products $(18.5 \%)$ and concentrate feeds $(16 \%)$ (Table 4). Further, among the grains, paddy grains, mustard grains, oilseeds etc. were mostly given depending upon the availability of grains in different seasons. Home- made by-products such as broken rice, rice bran, boiled rice, leafy vegetables in addition to kitchen wastes were supplemented to their backyard chicken. The present findings corroborated the results of Halima (2007) in Northern Ethiopia who reported that 96.8 per cent of the farmers supplied partial supplementation of feeds and 95.5 per cent of the feed was produced locally. More than two-third $(69.5 \%)$ of the farmers provided supplemental feeds by throwing or broadcasting on the ground, while remaining (30.5\%) respondents provided feeds in different types of containers (Table 4). Providing supplemental feed by throwing or broadcasting on the ground might cause

Table 4: Feeds and feeding practices adopted by the farmers

\begin{tabular}{|c|c|c|c|c|c|c|}
\hline Variables & $\begin{array}{l}\text { UBVZ } \\
\mathbf{N}=\mathbf{5 0}\end{array}$ & $\begin{array}{l}\text { LBVZ } \\
\mathrm{N}=\mathbf{5 0}\end{array}$ & $\begin{array}{l}\text { CBVZ } \\
\mathrm{N}=\mathbf{5 0}\end{array}$ & $\begin{array}{l}\text { NBPZ } \\
\mathrm{N}=\mathbf{5 0}\end{array}$ & $\begin{array}{l}\text { Overall } \\
\mathbf{N}=\mathbf{2 0 0}\end{array}$ & Chi square value \\
\hline \multicolumn{7}{|l|}{ Type of supplemental feeds (\%) } \\
\hline Concentrate feeds & 20.00 & 0.00 & 28.00 & 16.00 & 16.00 & $20.67 *$ \\
\hline Grains & 54.00 & 76.00 & 58.00 & 74.00 & 65.50 & \\
\hline By-product & 26.00 & 24.00 & 14.00 & 10.00 & 18.50 & \\
\hline \multicolumn{7}{|l|}{ Sources of supplemental feed (\%) } \\
\hline Commercial & 18.00 & 14.00 & 22.00 & 22.00 & 19.00 & 6.42 \\
\hline Homemade ingredients & 78.00 & 72.00 & 70.00 & 62.00 & 70.50 & \\
\hline Mill by-product & 4.00 & 14.00 & 8.00 & 16.00 & 10.50 & \\
\hline \multicolumn{7}{|c|}{ Type of grain/by-products supplemented (\%) } \\
\hline Paddy & 24.00 & 18.00 & 28.00 & 16.00 & 44.50 & 5.27 \\
\hline Broken rice & 56.00 & 54.00 & 52.00 & 68.00 & 34.50 & \\
\hline Kitchen wastes & 20.00 & 28.00 & 20.00 & 16.00 & 21.00 & \\
\hline \multicolumn{7}{|l|}{ Method of giving feeds (\%) } \\
\hline Broadcasting/ throwing & 50.00 & 78.00 & 76.00 & 54.00 & 69.50 & $12.80 *$ \\
\hline In containers & 50.00 & 22.00 & 24.00 & 46.00 & 30.50 & \\
\hline \multicolumn{7}{|c|}{ System of giving supplemental feeds (\%) } \\
\hline Given feed together & 78.00 & 84.00 & 68.00 & 58.00 & 71.50 & $14.01 *$ \\
\hline Given feed to chicks only & 0.00 & 4.00 & 2.00 & 0.00 & 1.50 & \\
\hline Given to feed chicks and hen only & 22.00 & 14.00 & 30.00 & 42.00 & 27.00 & \\
\hline \multicolumn{7}{|c|}{ Season mostly preferred for supplemental feeding (\%) } \\
\hline Pre-monsoon & 32.00 & 38.00 & 32.00 & 24.00 & 31.50 & $59.21 *$ \\
\hline Monsoon & 46.00 & 34.00 & 41.00 & 47.00 & 42.00 & \\
\hline Post-monsoon & 6.00 & 22.00 & 14.00 & 18.00 & 15.00 & \\
\hline Winter & 16.00 & 6.00 & 13.00 & 11.00 & 11.50 & \\
\hline \multicolumn{7}{|l|}{ Water provided (\%) } \\
\hline Yes & 16.00 & 4.00 & 8.00 & 10.00 & 9.50 & 4.36 \\
\hline No & 84.00 & 96.00 & 92.00 & 90.00 & 90.50 & \\
\hline \multicolumn{7}{|l|}{ Type of feeder and drinker used (\%) } \\
\hline Plastic containers & 4.00 & 6.00 & 6.00 & 10.00 & 6.50 & 6.34 \\
\hline Metallic utensils & 8.00 & 4.00 & 12.00 & 4.00 & 7.00 & \\
\hline Not used at all & 88.00 & 90.00 & 82.00 & 86.00 & 86.50 & \\
\hline \multicolumn{7}{|l|}{ Sources of water (\%) } \\
\hline Pond water & 32.00 & 28.00 & 34.00 & 36.00 & 32.50 & $31.18^{*}$ \\
\hline Well water & 22.00 & 22.00 & 40.00 & 52.00 & 34.00 & \\
\hline Any source of water & 46.00 & 50.00 & 26.00 & 12.00 & 33.50 & \\
\hline
\end{tabular}


wastage and contamination of feeds. Further, among containers, they used mostly broken earthen pots, unused plastic containers, plates, broken bowls etc. for feeding their chicken. Majority $(71.5 \%)$ of the farmers offered feed together to all age groups of birds, while some (27\%) offered feed to chicks and hen together and a few (1.5\%) offered to only hen. The present findings of supplying feeds to all age groups of birds together, which also corroborated the findings of Larbi et al. (2013) in South Tunisia. Assefa et al. (2019) reported that about 59 per cent of the chicken owners in Yeki and 64 per cent in Masha provided supplemental feed frequently while 68.4 per cent of the households in Andracha provided to all age groups equally in Ethiopia. Feeding all ages of chicken together indicated that chicks were deprived of supplemental feeds as they were unable to compete with older birds during feeding leading to poor nutrition and growth.

Feeding chicks separately might result in better growth and start up of the chicks. The present findings are in close accordance with the observations of Halima et al. (2007a) and Deneke (2013). Most (40\%) of the farmers preferred supplemental feed during monsoon followed by pre-monsoon $(31.5 \%)$, post-monsoon $(55 \%)$ and winter $(11.5 \%)$ season (Table 4). Feed supplementation during monsoon season might be due scarcity of scavenged feed resources during due to rain and flood. Reduced feed supplementation during winter season might be due to availability of scavenged feed because of harvesting of paddy and other crops. Regarding use of feeder and drinker, it was found that most $(86.5 \%)$ of the respondents did not use feeder and drinker, while only few of them used old containers as feeder and drinker made of plastic or metal. Use of feeder and drinker might reduce wastage and contamination of feed and water. In accordance with present findings, Billah et al. (2013) also reported that about 80 per cent of the farmers did not use feeders in Bangladesh. The survey revealed that most $(90.5 \%)$ of the respondents did not provide water to their birds, while only 9.5 per cent provided water to birds. This could be due to farmers' perception of availability of water round the year in the study areas. As water was not provided by majority of the respondents; hence most of the chicken consumed unclean water. The unclean water was one major source of contamination and infection in village chicken production, which might cause losses of chicken due to disease. The sources of water also varied with season and location.
More than one-third (34\%) of the respondents used well water, while 33.5 and 32.5 per cent of them used pond water or any stagnant water respectively (Table 4).

\section{Breeding and culling practices}

None of the farmers practiced systematic breeding practice for their indigenous chicken which might be due to lack of knowledge. Majority (86.5\%) of them used their own chicken's eggs for hatching purpose, while 11 per cent of them procured hatching eggs from their neighbours and only a few $(2.5 \%)$ purchased eggs from market for hatching purpose (Table 5). The farmers mostly used their home produced eggs for hatching purpose, which were in good agreement with the findings of Sankhyan et al. (2013) in India. All the farmers practiced natural incubation mostly by broody hen $(96.5 \%)$ or broody duck $(3.5 \%)$. This might be due lack of awareness or higher cost of the artificial incubator. Several workers (Halima et al., 2007; Dumrya et al., 2015; Alders et al., 2018) also reported natural incubation of chicken eggs. The selection of hatching eggs was not practiced by 68 per cent of the farmers, while rest practiced selection of eggs before incubation. The soundness of eggs was the main criteria for selection followed by cleanliness of egg shell. The survey also showed that the number of eggs set per broody hen or duck ranged from $13.06 \pm 0.26$ to $13.77 \pm 0.25$ with an overall mean value of $13.59 \pm 0.23$ (Table 5). Mostly, the size and mothering ability of the hen or duck was considered for the number of eggs set per hen or duck. The present findings were in close proximity with the findings of Kumar et al. (2013) in India and Nigussie et al. (2015) in Northern Ethiopia. None of the farmer maintained proper male-female ratio in their flock and was varied from farmer to farmer, which might be due to lack of knowledge, however it ranged from 1:5 to $1: 20$ with an average of 1:7.5. It was believed that more number of male birds in the flock might be attributed to cannibalism. Improper male-female ratio and uncontrolled breeding (inbreeding) might reduced genetic potential of indigenous chicken. Bikila (2013) reported that traditional poultry production system was characterized by lack of systematic breeding programme in Western Shewa. The village chicken breeding was completely uncontrolled and replacement stock produced through natural incubation using broody hen (Nigussie, 2011) in Ethiopia. 
Table 5: Breeding and culling practices adopted by respondents

\begin{tabular}{|c|c|c|c|c|c|c|}
\hline Variables & $\begin{array}{l}\text { UBVZ } \\
\mathbf{N}=\mathbf{5 0}\end{array}$ & $\begin{array}{l}\text { LBVZ } \\
\mathbf{N}=\mathbf{5 0}\end{array}$ & $\begin{array}{l}\text { CBVZ } \\
\mathbf{N}=\mathbf{5 0}\end{array}$ & $\begin{array}{l}\text { NBPZ } \\
\mathbf{N}=\mathbf{5 0}\end{array}$ & $\begin{array}{l}\text { Overall } \\
\mathbf{N}=\mathbf{2 0 0}\end{array}$ & $\begin{array}{l}\text { Chi square } \\
\text { value }\end{array}$ \\
\hline \multicolumn{7}{|c|}{ Source of hatching eggs (\%) } \\
\hline Own eggs & 86.00 & 90.00 & 88.00 & 82.00 & 86.50 & \multirow[t]{3}{*}{6.51} \\
\hline Purchased from neighbour & 14.00 & 10.00 & 8.00 & 12.00 & 11.00 & \\
\hline Market eggs & 0.00 & 0.00 & 4.00 & 6.00 & 2.50 & \\
\hline \multicolumn{7}{|l|}{ Incubation practice $(\%)$} \\
\hline Natural Incubation & 100.00 & 100.00 & 100.00 & 100.00 & 100.00 & \multirow[t]{2}{*}{00} \\
\hline Artificial Incubation & 0.00 & 0.00 & 0.00 & 0.00 & 0.00 & \\
\hline \multicolumn{7}{|l|}{ Means of incubation (\%) } \\
\hline Broody hen & 96.00 & 100.00 & 94.00 & 96.00 & 96.50 & \multirow[t]{2}{*}{2.81} \\
\hline Broody duck & 4.00 & 0.00 & 6.00 & 4.00 & 3.50 & \\
\hline \multicolumn{7}{|c|}{ Number of incubation per year (\%) } \\
\hline Once & 14.00 & 10.00 & 6.00 & 6.00 & 9.00 & \multirow[t]{3}{*}{3.74} \\
\hline Twice & 82.00 & 86.00 & 92.00 & 88.00 & 87.00 & \\
\hline Thrice & 4.00 & 4.00 & 2.00 & 6.00 & 4.00 & \\
\hline \multicolumn{7}{|c|}{ Selection of hatching eggs (\%) } \\
\hline Done & 24.00 & 34.00 & 28.00 & 42.00 & 32.00 & \multirow[t]{2}{*}{4.22} \\
\hline Not done & 76.00 & 66.00 & 72.00 & 58.00 & 68.00 & \\
\hline \multicolumn{7}{|c|}{ Criteria for selection of hatching eggs (\%) } \\
\hline Size of the egg & 16.00 & 8.00 & 12.00 & 20.00 & 14.00 & \multirow[t]{3}{*}{9.58} \\
\hline Soundness & 68.00 & 72.00 & 70.00 & 64.00 & 68.50 & \\
\hline Cleanliness & 16.00 & 20.00 & 18.00 & 16.00 & 17.50 & \\
\hline Number of eggs set/bird & 13.76 & 13.32 & 13.08 & 13.58 & $13.59 \pm 0.23$ & $\mathrm{P}=1.48$ \\
\hline \multicolumn{7}{|l|}{ Purpose of culling (\%) } \\
\hline Home consumption & 24.00 & 16.00 & 20.00 & 28.00 & 22.00 & \multirow{3}{*}{$36.79^{*}$} \\
\hline Sale & 54.00 & 66.00 & 56.00 & 70.00 & 61.50 & \\
\hline To entertain guests & 22.00 & 18.00 & 24.00 & 2.00 & 16.50 & \\
\hline \multicolumn{7}{|l|}{ Criteria for culling (\%) } \\
\hline Poor productivity & 24.00 & 14.00 & 18.00 & 22.00 & 19.50 & \multirow{4}{*}{22.27} \\
\hline Sickness & 12.00 & 30.00 & 36.00 & 16.00 & 28.50 & \\
\hline Old age & 22.00 & 22.00 & 20.00 & 44.00 & 27.00 & \\
\hline Surplus stocks & 42.00 & 34.00 & 26.00 & 18.00 & 30.00 & \\
\hline \multicolumn{7}{|l|}{ Age of culling (\%) } \\
\hline 6-7 months & 50.00 & 62.00 & 54.00 & 66.00 & 58.00 & \multirow{4}{*}{8.38} \\
\hline 1 year & 34.00 & 16.00 & 22.00 & 18.00 & 22.50 & \\
\hline 2 years & 12.00 & 14.00 & 12.00 & 10.00 & 12.00 & \\
\hline Not recorded & 4.00 & 8.00 & 12.00 & 6.00 & 7.50 & \\
\hline
\end{tabular}

Most $(61.5 \%)$ of the respondents culled surplus birds for sale, while some (22\%) of them culled chicken for self-consumption and a few (16.5\%) practiced culling to entertain guests (Table 5). Most of the farmers culled their surplus chicken by sale that indicated income generation through indigenous chicken rearing, while they seldom consumed surplus birds to ensure their nutritional security. Income from selling of surplus stock directly came to women as indigenous chicken farming was mostly headed by women and thus helped in women empowerment. The findings were in concurrent with the findings of Kumar et al. (2013) and Wong et al. (2017). The criteria for culling were found as surplus stock $(30 \%)$, senility $(27 \%)$, sickness $(23.5 \%)$ and poor productivity (19.5\%). In most $(58 \%)$ of the cases, the farmers culled their surplus stocks (male and female) chicken at the age 6 to 7 months, while rest of them culled their chicken at 1 and 2 years age (Table 5). Kumar et al. (2013) also reported similar culling age 
for male chicken; however, females were culled after 3 years of age in Kerala. In support of this study, Melese and Melkamu (2014) and Halima (2007) reported that about $74.7 \%$ of the reasons for culling of chicken in North West Ethiopia are poor productivity, old age and sickness as a whole.

\section{Incidence of diseases and its control measures}

The results presented in Table 6 , revealed that most $(43.5 \%)$ of the respondents observed greenish diarrhoea as one of the important symptoms during disease outbreak, followed by ruffled feather (36.5\%) and huddling together $(11.5 \%)$. The study showed that majority $(54.5 \%)$ of the respondents did not treat their sick birds, which might be attributed to lack knowledge of disease management and inadequate veterinary services. The present findings were in line with Oladinnu and Fatuase (2014), who reported that rural poultry owners were unconcerned about chicken disease. Newcastle (Ranikhet) disease was the most fatal disease that caused maximum mortality in a flock as reported by most $(84.5 \%)$ of the farmers (Table 6). The present findings were in close proximity with the results of Moreda et al. (2013) and Nigussie et al. (2015) who also observed that New Castle Disease was the major disease in Ethiopia. The disease was tentatively diagnosed on the basis of signs and symptoms such as coughing, sneezing, nasal discharge and heavy morbidity with mortality followed by post-mortem examination of the dead birds under field condition.

The higher mortality due to Newcastle disease might be due to lack of veterinary services to rural chicken farmers as it is a highly infectious disease and can cause 100 per cent mortality in a flock (Alders et al., 2010; Samal, 2011). Majority (54.5\%) of the respondents did not treat their sick birds, while 18 per cent of them consult with veterinarian and rest slaughtered or sold the sick birds immediately. Majority $(95.5 \%)$ of the farmers did not vaccinate their birds against any disease, while only a few (4.5\%) farmers

Table 6: Disease incidences and its control measures

\begin{tabular}{|c|c|c|c|c|c|c|}
\hline Variables & $\begin{array}{l}\text { UBVZ } \\
\mathbf{N}=\mathbf{5 0}\end{array}$ & $\begin{array}{l}\text { LBVZ } \\
\mathrm{N}=\mathbf{5 0}\end{array}$ & $\begin{array}{l}\text { CBVZ } \\
\mathbf{N}=\mathbf{5 0}\end{array}$ & $\begin{array}{l}\text { NBPZ } \\
\mathrm{N}=\mathbf{5 0}\end{array}$ & $\begin{array}{l}\text { Overall } \\
\mathrm{N}=\mathbf{2 0 0}\end{array}$ & $\begin{array}{l}\text { Chi square } \\
\text { value }\end{array}$ \\
\hline \multicolumn{7}{|c|}{ Important symptoms observed in disease outbreak (\%) } \\
\hline Greenish diarrhea & 64.00 & 56.00 & 24.00 & 30.00 & 43.50 & \multirow{4}{*}{$42.27 *$} \\
\hline Ruffled feather & 20.00 & 22.00 & 54.00 & 50.00 & 36.50 & \\
\hline Huddling together & 16.00 & 18.00 & 6.00 & 6.00 & 11.50 & \\
\hline Others & 0.00 & 4.00 & 16.00 & 14.00 & 8.50 & \\
\hline \multicolumn{7}{|l|}{ Treatment of sick birds (\%) } \\
\hline Consulted with veterinarian & 22.00 & 6.00 & 20.00 & 24.00 & 18.00 & \multirow{4}{*}{$23.73 *$} \\
\hline Self-treated & 10.00 & 16.00 & 6.00 & 14.00 & 11.50 & \\
\hline Slaughtered or sold & 8.00 & 34.00 & 12.00 & 10.00 & 16.00 & \\
\hline Not treated & 60.00 & 44.00 & 62.00 & 52.00 & 54.50 & \\
\hline \multicolumn{7}{|l|}{ Practice of vaccination (\%) } \\
\hline Yes & 4.00 & 0.00 & 4.00 & 10.00 & 4.50 & \multirow{2}{*}{5.93} \\
\hline No & 96.00 & 100.00 & 96.00 & 90.00 & 94.50 & \\
\hline \multicolumn{7}{|l|}{ Practice of deworming (\%) } \\
\hline Yes & 0.00 & 0.00 & 0.00 & 0.00 & 0.00 & \multirow{2}{*}{00} \\
\hline No & 100.00 & 100.00 & 100.00 & 100.00 & 100.00 & \\
\hline \multicolumn{7}{|l|}{ Causes of mortality (\%) } \\
\hline Diseases & 68.00 & 86.00 & 78.00 & 82.00 & 78.50 & \multirow{3}{*}{5.93} \\
\hline Predation & 24.00 & 10.00 & 14.00 & 14.00 & 15.50 & \\
\hline Senility & 8.00 & 4.00 & 8.00 & 4.00 & 6.00 & \\
\hline \multicolumn{7}{|l|}{ Most fatal disease (\%) } \\
\hline Newcastle disease & 86.00 & 90.00 & 78.00 & 21.00 & 84.50 & \multirow{3}{*}{9.38} \\
\hline Fowl pox & 4.00 & 2.00 & 16.00 & 6.00 & 7.00 & \\
\hline Others & 10.00 & 8.00 & 6.00 & 10.00 & 8.50 & \\
\hline
\end{tabular}


vaccinated their birds against Newcastle (Ranikhet) Disease. Similarly Nigussie et al. (2015) also reported that village chicken owner had no culture of vaccination against disease. Lack of awareness about the disease and presence of chicken vaccines, lack of attention to village chicken, low availability of vaccines and absence of small doses of vaccines for small number of flocks were the major reasons for lack of vaccination against diseases. None of the farmers practiced deworming. Majority of the farmers $(78.5 \%)$ reported that disease was the most important cause of mortality among birds, while predation and senility caused mortality in case of 15.5 and 6.0 per cent of the farmers (Table 6).

\section{Marketing}

The indigenous chicken was reared for both egg and meat production. The chickens were sold as live chicken mostly when they need cash. In most of the cases, farmers sold their chickens to neighbours, hawkers and to people who need chicken meat for weddings, birthday parties and other celebrations. Farmers rarely sold their chicken at market might be due to higher transportation cost and lack of access to chicken market (Abdelqader et al., 2007). There were no specific market where farmers could sell chickens and eggs. Hence farmers preferred to sale chicken at the doorstep to the middlemen (local vendor) resulted in reduced price of their produce due to exploitation by middlemen. Awol (2010) also reported that village chicken farmers were not in a position to get expected return from the sale of chicken in North West Ethiopia due to low price, low marketing output and long distance to reliable market. Getachew et al. (2015) also reported that informal marketing of poultry and poultry products at open markets were common in Eastern Ethiopia, where live chicken and eggs were sold on road-side stops. Most of the consumers preferred to purchase fresh eggs directly from the farmers. However, the study revealed that around 20 to $25 \%$ of the eggs and 10 to $15 \%$ of live chicken were sold directly to the consumers. The demand of local chicken and egg was always high than commercial eggs and birds and fetched always higher prices in the markets. However, the demand of local chicken increased further in some festive occasions such as Bihu, Eid, Kali Puja, Durga Puja etc. Getachew et al. (2015) reported that there was seasonal variation of demand for eggs and live chicken in Ethiopia. The demand decreased during fasting period for orthodox
Christian and the demand increased during holiday's festivities in Ethiopia.

\section{Marketing channels for chicken egg}

Four marketing channels were identified as follows:

Channel I: Producer $\rightarrow$ Consumer

Channel II: Producer $\rightarrow$ Local Vendor $\rightarrow$ Consumer

Channel III: Producer $\rightarrow$ Local Vendor $\rightarrow$ Retailer $\rightarrow$ Consumer

Channel IV: Producer $\rightarrow$ Local Vendor $\rightarrow$ Hatchery man (In LBVZ particularly)

\section{Marketing channels for live chicken}

Four marketing channels were identified as follows:

Channel I: Producer $\rightarrow$ Consumer

Channel II: Producer $\rightarrow$ Local Vendor $\rightarrow$ Consumer

Channel III: Producer $\rightarrow$ Local Vendor $\rightarrow$ Retailer $\rightarrow$ Consumer

Channel IV: Producer $\rightarrow$ Local Vendor $\rightarrow$ Trader $\rightarrow$ Retailer $\rightarrow$ Consumer

\section{CONCLUSION}

It may be concluded that indigenous chicken farming has been contributing significantly towards the livelihood and nutritional security of rural households. It is pro-poor and eco-friendly approach and forms the base of women empowerment for rural women. The genetic potential of the indigenous chicken can be exploited to their fullest extent by proper housing, feeding, breeding and other improved management practices. As, Newcastle disease is the most fatal disease and causes maximum mortality in indigenous chicken, which also hinders the production significantly. Marketing is also one of the major constraints faced by poultry farmer study area. Proper training of the rural farmwomen for improved production technology, development of community vaccinator and better veterinary extension services can play a pivotal role for sustainable development of indigenous chicken farming in rural India. 


\section{REFERENCES}

Abdelqader, A., Wollny, C.B.A. and Gauly, M. 2007. Characterization of local chicken production systems and their potential under different levels of management practice in Jordan. Trop. Anim. Health Prod., 39: 155-164.

Alders, R.G., Bagnol, B. and Young, M.P. 2010. Technically sound and sustainable Newcastle disease control in village chickens: Lessons learnt over fifteen years. World's Poult. Sci. J., 66: 433-440.

Alders, R.G., Dumas, S.E., Rukambile, E., Magoke, G., Maulaga, W., Jong. J. and Costa, R. 2018. Family poultry: Multiple roles, systems, challenges and option for sustainable contributions to household nutrition security through planetary health lens. Mater. Child Nutri., 14: e12668.

Assefa, H., Melesse, A. and Taye, M. 2019. Characterization of indigenous chicken production systems in Sheka zone, south western Ethiopia. Inter. J. Res. Agric. Food Sci., 5(2): 1-16.

Awol, Z. 2010. Analysis of poultry market chain: the case of Dale and Alba 'Special' words of SNNPRS, Ethiopia.

BAHS. 2016. Basic Animal Husbandry Statistics, Department of Animal Husbandry and Dairying and Fisheries (DAHD), Ministry of Agriculture, Government of India, Krishi Bhawan, New Delhi.

Balamurugan, P., Senthilkumar, A. and Murugesan, S. 2017. An analysis on socio-economic profile of backyard poultry farmers in Theni district of Tamil Nadu. Inter. J. Sci. Environ. Tech., 6: 3513- 3519.

Bharti, R., Sagar, M., Chander, M., Singh, D. and Yadav, P. 2018. Socio-Economic Status of Backyard Poultry Rearing Rural Women of Bundelkhand Region of Uttar Pradesh. Inter. J. Lives. Res., 8: 158-163.

Bikila, N. 2013. Study on production practices, productivity and egg quality of village chicken in Chelliya District Western Shewa, Ethiopia, A Thesis submitted to the school of graduate studies (School of Animal and Range Sciences), Haramaya Universitry, Ethipopia.

Billah, S. M., Nargis, F., Hossain, M.E., Howlider, M.A.R. and Lee, S.H. 2013. Family poultry production and consumption patterns in selected households of Bangladesh. African $J$. Poult. Fmg., 1: 8-14.

Chaturvedani, A. K., Lal, N., Pratap, J. and Kalpana, D. 2016. Housing, feeding and breeding practices of backyard poultry production in Chattisgarh, India. Inter. J Agril. Sci., 8: 20002003.

Chutia, H. 2010. A study on some aspects of indigenous chicken in Dhemaji district of Assam. (M.V.Sc Thesis) Assam Agricultural University, Guwahati-22, Assam, India.

Demeke, S. 2008. Ethiopia: Poultry sector country review. FAO, Rome, Italy.
Dumrya, S., Ghosh, S. and Goswami, R. 2015. Characterization of backyard poultry farming in Indian Sundarban region. Indian J. Poult. Sci., 50: 90-95.

Fida, N., Abebe, B. and Haile, D. 2018. An assessment of socioeconomic features of village chicken farmers in Ethiopia. African J. Poult. Fmg., 6: 225-236.

Fisseha, M., Abera, M. and Tadelle, D. 2010a. Assessment of village chicken production system and evaluation of the productive and reproductive performance of local chicken ecotype in Bure district, North West Ethiopia. African J. Agric. Res., 5: 1739-1748.

Gazi, A. M., Goswami, A., Mazumdar, D. and Pal, B. 2014. Backyard Poultry Farming System: Women and Its Role. Inter. J. Dev. Res., 4: 1122-1124.

Getachew T, Kebede E, Ameha N. and T. Terefe A. 2015. Village Chicken Husbandry Practice, Marketing and Constraints in Eastern Ethiopia. J. World's Poult. Res., 5: 104-108.

GOI. 2019. 20 ${ }^{\text {th }}$ Livestock Census-2019. Ministry of Fisheries, Animal Husbandry and Dairying, Department of Animal Husbandry and Dairying, Government of India, Krishi Bhawan, New Delhi.

Halima, H. 2007. Phenotypic and genetic characterization of indigenous chicken population in North-West Ethiopia. $\mathrm{Ph}$. D Thesis submitted to University of the Free State, Bloemfontein, South Africa.

Halima, H., Neser, F.W.C., Mark-Koster, E. V. and Kock, A. D. 2007. Village-based indigenous chicken production system in north-west Ethiopia. Trop. Anim. Health Prod., 39: 189-197

Halima, H., Neser, F.W.C., Marle-Koster, E. and Kock, A.D. 2007a. Phenotypic variation of native chicken populations in northwest Ethiopia. Trop. Anim. Health Prod., 39: 507-513.

Hussain, K., Chaturvedani, A.K., Lal, N. and Gupta, S. 2017. Backyard poultry management practices in rural hilly areas of Jammu and Kashmir. Indian J. Hill Fmg., 30: 129-131.

Keqa, B., Abdallh, M.E., Glatz, P.C. and Iji, P.A. 2017. Flock structure and phenotypic characteristics of local chickens in the Solomon Islands. Trop. Anim. Poult. Sci., 1: 42-57.

Kumar, P. G., Churchil, R.R., Jalaludeen, A., Narayanankutty, K., Joseph, L., Kannan, A. and Anitha, P. 2013. A survey on village chicken production in Kerala state of India. World's Poult. Sci. J., 69: 917-930

Larbi, M. B., M'hamdi, N. and Haddad, B. 2013. Indigenous chicken production systems in villages in the south of Tunisia. Lives. Res. Rur. Dev., 25.

Mandal, M. K., Khandekar, N. and Khandekar, P. 2006. Backyard poultry farming in Bareilly district of UP, India: Analysis. Lives. Res. Rur. Dev., 18. 
Mapiye, C. and Sibanda, S. 2005. Constraints and opportunities of village chicken production systems in small holder sector of Rushinga districts of Zimbabwe. Lives. Res. Rur. Dev., 17.

Melese, G. and Melkamu, B. 2014. Assessment of chicken production under farmer's management condition in East Gojam Zone of Amaraha Regional State, Ethiopia. Greener J. Anim. Breed. Genetic., 1: 1-10

Moges, F., Mellesse, A. and Dessie, T. 2010. Assessment of village chicken production system and evaluation of the productive and reproductive performances of local chicken ecotype in Bure district, North west Ethiopia. African J. Agril. Res., 5: 1739-1748.

Moreda, E., Hareppal, S., Johansson, A., Sisaye, T. and Sahile, Z. 2013. Characteristics of Indigenous Chicken Production System in South West and South Part of Ethiopia. British J. Poult. Sci., 2: 25-32.

Muchadeyi, F. C., Sibanda, S., Kusian, J. and Makuza, S. (2004). The village chicken production system in Rushinga District of Zimbabwe. Lives. Res. Rur. Dev., 16 (6):

Nigussie, D. 2011. Breeding programme for indigenous chicken in Ethiopia: analysis of diversity in production systems and chicken populations, Ph.D Thesis, Wageningen University, the Netherlands.

Nigussie, H., Kebede, K. and Ameha, K. 2015. Survey on indigenous chicken production and utilization systems in southern zone of Tigray, Northern Ethiopia. Food Sci. Qua. Managmt., 45: 91-99

Oladunni, M.E. and Fatuase, A.I. 2014. Economic Analysis of Backyard Poultry Farming in Akoko North West Local Government Area of Ondo State, Nigeria. Global J. Biol. Agric. Health Sci., 3: 141-147.

Rawat, S.K., Gupta, R. and Narain, S. 2015. Study on the Performance of Backyard Poultry Production Reared By Rural Woman in Mahoba. Indian Res. J. Ext. Edu., 15: 24-28
Roseline, O., Emmanuel, M and Manny, M. 2015. Evaluation of local chicken production in Kogi State of Nigeria. Inter. J. Agril. Poli. Res., 3: 377-381.

Samal, S.K. 2011. Newcastle disease and related avian paramyxovirus. In: Samal, S.K. (Ed.), The Biology of Paramyxoviruses. Caister Academic Press, Norfolk, United Kingdom, pp. 69-114.

Sankhyan, V., Katoch, S., Thakur, Y.P., Dinesh, K., Patial, S. and Bhardwaj, N. 2013. Analysis of characteristics and improvement strategies of rural poultry farming in north western Himalayan state of Himachal Pradesh, India. Lives. Res. Rur. Dev., 25: 41-48.

Shahjahan, M. and Bhuiyan, A.K.F. H. 2016. Socio-economic condition and indigenous poultry production scenario in a selected cluster area of Bangladesh. Asian-Australian J. Biosci. Biotech., 1: 557-563.

Shinde, P. K., Srivastava, N. and Sashidhar, P.V.K. 2006. Adaptive research interventions on household poultry: lessons learned and feedback for further research. In poultry research priorities to 2020, Proceedings of National Seminar, CARI, Izzatnagar, 2-3 November, 2006 (pp: 239-243)

Snedecor, G.W. and Cochran, W.G. 1994. Statistical Methods; $6^{\text {th }}$ Edition. Oxford and IBH Publishing Co. Calcutta, 1994.

Tudu, N.K., Roy, D.C. and Goswami, K.K. 2015. Socioeconomic profile of tribal poultry farmers in Nadia district of West Bengal. Global J. Res. Anal., 4: 8-10

Wang, J.T., De Bruyn, J., Bagnol, B., Grieve, H., Li, M., Pym, R. and Alders, R.G. 2017. Small-scale poultry and food security in resource-poor settings: A review. Global Food Secu. http:// dx.doi.org/10.1016/j.gfs.2017.04.03

Yusuf, S.F.G., Lategan, F.S. and Masika P.J. 2014. Characterization of indigenous poultry production system in Nkonkobe Municipality, Eastern Cape Province South. $J$. Agril. Sci., 5: 31-34. 